\title{
Formal allocation models for urban activities
}

\section{Summary}

1. Introduction

2. Formal demand allocators and properties.

3. Allocators for urban activities

4. Implementation of the model

5. Uses of the model

1. Introduction

Empirical studies of urban economic activities a re now classical. ${ }^{1}$ They relate the absolute amount of employment in given economic sectors or the employment shares, either to total population, or to some basic employment.

No formal consistent model is known to us. On the other hand, spatial characteristics are generally absent; the authors implicitly assume that sufficient space will be available. As we will see, the situation is analogous to that of a consumer confronted only with goods at constant prices.

This paper proposes two allocation models for urban activities; in a second phase of our reserach we attempted to estimate the parameters of one of them on the basis of available U.S. data.

\section{Formal demand allocators and properties}

Demand allocators have been intensively studied in recent years. ${ }^{2}$ Their formal properties could be of some use in the analysis of urban activity patterns. Two models will be shortly analyzed hereafter.

\subsection{Linear expenditure systems}

The linear expenditure system is written as

$$
p_{i} q_{i}=p_{i} q_{i}+b_{i}\left(d-\Sigma_{j} p_{j} q_{j}\right)
$$

where

$$
\begin{aligned}
& \mathrm{p}_{i}= \text { price of good } i ; \\
& \mathrm{q}_{i}= \text { quantity consumed of good } i ; \\
& \bar{q}_{t}= \text { minimal quantity consumed of good } i \text { whatever its price } \\
& \quad\left(p_{i} \bar{q}_{i}=\text { "committed expenditure" on good } i\right) ;
\end{aligned}
$$

* The present study was made when the author was visiting the Departments of Economics and of City and Regional Planning (M. I. T.), and was also a member of the Joint Center for Urban Studies of Harvard University and M.I. T. 
$d=$ total expenditure at current prices;

$\Sigma_{j} p_{j} q_{j}=\begin{aligned} & \text { total committed expenditures }\left(d-\Sigma_{j} p_{j} \bar{q}_{j}=s=\text { "supernumerary }\right. \\ & \text { expenditures") }\end{aligned}$

$b_{i}=$ allocator of supernumerary expenditures

$\left(\Sigma_{i} b_{i}=1, b_{i}>0\right)$.

One verifies easily the additivity of the system:

$$
\sum_{i} p_{i} q_{i} \equiv d
$$

The typical elasticities of the system are:

$$
\frac{E q_{i}}{E d} \underset{\text { def }}{\equiv \frac{E p_{i} q_{i}}{E d}}=b_{i} a_{i}^{-1}>0
$$

where $a_{i}$ is the budget-share of $\operatorname{good} i, p_{i} q_{i} d^{-1}$.

$$
\begin{aligned}
& \frac{\mathrm{Eq}_{i}}{\mathrm{Ep}_{i}} \mathrm{~d} \overline{\overline{\mathrm{e}}} \frac{\mathrm{Ep}_{i} \mathrm{q}_{i}}{\mathrm{Ep}_{i}}-1=\frac{\left(1-\mathrm{b}_{i}\right) \bar{q}_{i}}{\mathrm{q}_{i}}-1 \\
& \text { with }-1<\frac{\mathrm{Eq}_{i}}{\mathrm{Ep}_{i}}<0
\end{aligned}
$$

for normal conditions $\left(q_{i} q_{i}^{-1}<1\right)$.

$$
\frac{E q_{1}}{E p_{j}} \equiv \frac{E p_{i} q_{i}}{E p_{j}}=-\frac{b_{i} p_{j} \bar{q}_{j}}{p_{j} q_{j}}<0
$$

The Slutsky-elasticities are:

$$
\begin{aligned}
& \sigma_{i i}=E^{*}{ }_{i i} a_{i}{ }^{-1}+E^{*}{ }_{i}=a_{i}{ }^{-1}\left(1-b_{i}\right) \frac{p_{i} q_{i}}{p_{i} q_{i}}-1<0 \\
& \sigma_{i j}=E^{*}{ }_{i j}{ }^{a}{ }_{j}^{-1}+E^{*}{ }_{i}=b_{i}{ }^{-1}{ }^{-1} d^{-1}\left(d^{-}-p_{j} q_{j}{ }^{a}{ }_{j}^{-1}\right)>0
\end{aligned}
$$

Equations [4] and [7] show that the system is restricted in that it does not allow for price-elastic and complementary goods.

\subsection{Log-linear allocators}

The log-linear allocator is written as:

$$
p_{i} q_{i}=\frac{\alpha_{i}\left(p_{i} d^{-1}\right) \beta_{i} \cdot d}{\sum_{\gamma} \alpha_{j}\left(p d^{-1}\right) \beta_{\gamma}}
$$

the variables being the same as defined in $2.1, \alpha_{i}$ and $\beta_{i}$ being non-constrained parameters. The system is clearly additive. Its typical elasticities are

$$
\begin{aligned}
& \frac{\mathrm{Eq}_{i}}{\mathrm{Ed}} \underset{\operatorname{def}}{E} \frac{\mathrm{Ep}_{i} \mathrm{q}_{i}}{\mathrm{Ed}}=1-\beta_{i}+\sum_{j} a_{j} \beta_{j} \\
& \frac{E q_{i}}{E p_{i} \text { def }} \equiv \frac{E p_{i} q_{i}}{E d}-1=\left(1-a_{i}\right) \beta_{i}-1
\end{aligned}
$$




$$
\frac{E q_{i}}{E p_{j}} \equiv \frac{E p_{i} q_{i}}{\operatorname{def}}=-a_{j} \beta_{j}
$$

and the Slutsky-elasticities may be computed as:

$$
\begin{aligned}
& \sigma_{i i}=\left(\frac{1-a_{i}}{a_{i}}\right)\left[\left(1-a_{i}\right) \beta_{i}-1\right]+\sum_{j \neq i} a_{j} \beta_{j} \\
& \sigma_{i j}=1-\left(\beta_{i}+\beta_{j}\right)+\sum_{j} a_{j} \beta_{j}=\frac{E q_{i}}{E d}-\beta_{j} \geqslant 0
\end{aligned}
$$

The only limitation of the model is the equality of all cross-elasticities [11] for given $j,{ }_{i}$

\section{Allocators for urban activities}

The main problem is to find an analog for the price paid by the consume r.

It appears to us that spatial density could play this role in an u rban allocator. Models [1] and [8] would then take the form:

$$
\begin{aligned}
& \left.\frac{E_{i} S_{i}}{S_{i}} \equiv E_{i}=\frac{E_{i}}{S_{i}} \cdot \bar{s}_{i}+b_{i} \underset{j}{(E}-\sum_{j} \cdot \frac{E_{j}}{S_{j}} \cdot \bar{S}_{j}\right) \\
& \frac{E_{i}}{S_{i}} S_{i} \equiv E_{i}=\frac{\alpha_{1}\left(E_{i} S_{i}^{-1} E^{-1}\right) i}{\sum_{j} \alpha_{j}\left(E_{j} S_{j}^{-1} E^{-1}\right) B_{j}}
\end{aligned}
$$

where

$$
\begin{aligned}
E_{i} & =\text { sectoral employment; } \\
E & =\text { total employment } \\
\mathrm{S}_{i} & =\text { surface occupied by activity } i
\end{aligned}
$$

Equations [14] and [15] can be rewritten as

$$
\begin{aligned}
& D_{i} S_{i} \equiv E_{i}=D_{i} \bar{S}_{i}+b_{i}\left(E-\sum_{j} D_{j} \bar{S}_{j}\right) \\
& D_{i} S_{i} \equiv E_{i}=\frac{\alpha_{i}\left(D_{i} E^{-1}\right)^{\beta_{i}} \cdot E}{\sum_{j} \alpha_{j}\left(D_{j} E^{-1}\right)^{\beta_{j}}}
\end{aligned}
$$

Equation [16] appears to be a bit difficult to interpret: a minimal surface, $S_{i}$, whatever the density, $D_{i}$ does not seem to be a very common concept, unless specialists in urban land use can give it some operational meaning. Moreover,

$$
\frac{E\left(E_{i}\right)}{E D_{i}}=\frac{\left(1-b_{i}\right) \bar{S}_{i}}{S_{i}}>0
$$

so that employment never reacts negatively to density (unless $s_{i}>0$, of which the meaning is even less clear). 
For thegge reasons, equation[17] seems to be more adapted. Meaningful elasticities would be:

$$
\text { a) } \frac{E\left(S_{i}\right)}{E(E)}=1-\beta_{i}+\sum_{j} a_{j} \beta_{j}
$$

measuring the relative evolution of sectoral land use, $S_{i}$, for a given relative evolution of total employment, E, all densities constant;

$$
\text { b) } \sigma_{i i}=\frac{\left(1-a_{i}\right)}{a_{i}}\left[\left(1-a_{i}\right) \beta_{i}-1\right]+\sum_{j \neq i} a_{j} \beta_{j}
$$

measuring the relative evolution of sectoral land use, $\mathrm{S}_{\mathrm{i}}$, for a given relative evolution of sectoral density, $D_{i}$, all other densities constant and total employment being adapted to the new density.

$$
\text { c) } \sigma_{i j}=\frac{E\left(S_{i}\right)}{E(E)}-\beta_{j}
$$

measuring the relative evolution of sectoral land use, $\mathrm{S}_{\mathrm{i}}$ for a given relative evolution of sectoral density of sector , $D_{j}$, all other densities constant and total employment being adapted to the new density. Sectors $i$ and $j$ would appear to be competing or complementary, with respect to densities accarding to whether $\sigma_{i j}>$ or $<0$.

\section{Implementation and uses of the model}

In order to implement the model one would need a sectoral breakdown of employment, together with estimates of occupied surfaces, for different cities and/or different years. For self-contained metropolitan areas, housing might be included, $\underline{\mathrm{P}}$ (population) substituted for the corresponding $\mathrm{E}_{\mathrm{i}}, \frac{\mathrm{P}}{\mathrm{Sh}}$ measuring housing density.

This program has been implemented as follows.

\section{1 Source of data}

Land use data are referred to in some classical works on the subject ${ }^{7}$. Tables in Bartholomew (1955) give absolute and percentage of value of land uses in ceritral cities. For 37 of them out of 53,8 the following grouping ${ }^{9}$ has been made.

\section{Our Categories}

a. Residential use

b. Use by services

c. Industrial use

d. Semi-public and public use

\section{Bartholomew's Categories}

aa. Single family dwellings

ab. Two-family dwellings

ac. Multi-family dwellings

ba. Commerical use.

ca. Light industry

cd. Heavy industry

d. Semi-public and public use.

Table 1 displays the data in columns (C), (D), (E), (F); colume (B) lists the years of observation. For the occupational side of the picture, use was made of the 1952 and 1949 City and County Data books, except for population 
(column G) taken from Bartholomew (1955) and corrected downward for "Institutional population" (included in column $\mathrm{J}$ ).

The other occupational categories are as listed below. They have all been extrapolated or retropolated on a basis proportional to a linear evolution of total industrial employment ("all employees") between 1939 and 1947; to compute these factors, 1939 "production-workers" figures were blown up on the basis of 1947 ratios between "all employees" and "production workers".

\section{Categories}

b. Services

c. Industry

d. Public and semi-public activities
Content

ba. Retail trade:

i) Active proprietors of unincorporated businesses.

ii) Total paid employees

bb. Personal, business and repair services.

i) as sub (ba).

bc. Hotels (total paid employees)

bd. Amusement business (id).

be. Finance, Insurance and Real Estate (id).

bf. Professorial and related services (id).

ca. Industry (all employees)

cb. Wholesale trade (id).

da. Institutional population

db. City government

dc. City schools

i) Teachers

ii) Enrollment

dd. Hospitals

i) Beds

ii) Personnel 
(A)

(B)

Year of

Observation

\section{City}

1. Baton Rouge, La.

2. Battle Creek, Mich.

3. Jefferson City, Mo.

4. Kankakee, Ill.

5. Mason City, Iowa

6. Muskogee, Okl.

7. Petersburg, Va.

8. Quincy, Ill.

9. Rock Island, Ill.

10. Roswell, New Mex.

11. Santa Fe, New Mex.

12. West Palm Beach, Fla.

13. Bringhamton, N. Y.

14. Davenport, Iowa

15. Decatur, Ill.

16. Greenville, S.C.

17. Hamilton, Ohio

18. Lansing, Mich.

19. Lincoln, Neb.

20. Portsmouth, Va.

1948

1945
1938

1967

1937

1951
(C)

(D)

(E)

(F)

(G)

(H)

(I)

( J)

(K)
Population and Employment

Total

(G) through (J)

(5)

(1)

(2)

(3)

(4)

$81.66 \quad 265.61$

$305.30 \quad 339.40$

$77.90 \quad 462.90$

$92.20 \quad 81.90$

$34,600 \quad 13,988 \quad 5,413$

$43,360 \quad 8,121 \quad 12,383$

$20,000 \quad 4,419 \quad 3,014$

$22,170 \quad 4,446 \quad 2,901$

$25,250 \quad 3,542 \quad 2,996$

9,102

14,094

8,160

8,362

5,180

$940.60 \quad 56.90$

467.60

267.10

$1,522.62$

107.92

49.29

, $597.50 \quad 87.20$

$1,597.50$

91.90

69.37

61.90

221.57

549.32

273.36

167.30
$214.40 \quad 163.40$

$221.20 \quad 283.40$

185.64

283.40
960.09

\section{7,150}

30,380

(5,

42,350

5,369
6,505

6,505
5,783

2,021

5,117

6,072

10,802

16,521

6,227

3,842

$\begin{array}{rrrr}20,390 & 3,263 & 598 & 5,892\end{array}$

$53.24 \quad 604.80$

$138.60 \quad 274.00$

$815.56 \quad 56.98$

$1,614.40 \quad 266.00$

$1,853.60 \quad 288.70$

$2,708.00 \quad 116.00$

288.70

274.00
593.00

$2,004.70$

123.30

259.90

722.00

$23,600 \quad 3,490 \quad 800$

$43,750 \quad 8,603 \quad 2,102$

$82,100 \quad 14,429 \quad 13,312$

$\begin{array}{rrr}74,700 & 11,689 & 7,997\end{array}$

$57,350 \quad 6,483 \quad 7,094$

6,180

13,623

26,114

12,307

9,618

$57,817 \quad 12,465 \quad 7,871$

$54,400 \quad 6,986 \quad 15,723$

12,892

$2,790.80 \quad 250.00$

$1,581.10$

188.20

746.30

$3,349.00$

95.10
131.20

182.00

313.80

308.20

465.30

$208.001,064.00$

$\begin{array}{rrr}83,100 & 7,821 & 13,456 \\ 96,700 & 23,512 & 12,446\end{array}$

9,260

9,373

26,432

19,020
63,103

77,957

35,593

37,879

36,968

55,342

58,523

60,432

58,842

30,143

34,070

68,078

135,955

106,693

80,545

91,045

86,369

113,750

149,090

112,324 
(A)

Observation

City

21. Racine, Wis.

22. St. Petersburg, Fla.

23. Sioux Falls, S. D.

24. Schenectady, N. Y.

25. Topeka, Kansas

26. Corpus Christi, Tex.

27. Des Moines, Iowa

28. Kansas City, Kansas

29. Oklahoma City, Okla.

30. Richmond, Va.

31. Utica, N. Y.

32. Wichita, Kansas

33. Dallas, Texas

34. Dayton, Ohio

35. Memphis, Tenn.

36. Newa rk, N. J.

37. St. Louis, Missouri

*includes railroad property

(D)

(E)

(F)

(G)

(H)

(I)

(J)

Land Use (acres)

(2)

163.40

185.70

185.70
148.80

1941

1949

1945

1942

1951

1939

1938

1945

1942

1948

1944

1944

1956

1949

1945

1935
(1)

$2,466.00$

$1,579.40$

$1,869.90$

$2,577.00$

4, 035.00

$7,523.80$

$3,481.50$

$6,312.65$

$5,429.40$

$2,018.60$

$5,324.70$

$12,262.15$

$6,657.00$

$8,745.60$

$2,902.50$

$12,323.40$
205.60
127.50

458.90

216.70

350.24

412.40
Population and Employment

Total

(G) through $(\mathrm{J})$

(5)

90,506

80,670

81,651

142,203

102,725

$269.701,371.50$

$554.10 \quad 739.00$

$60,700 \quad 9,537$

$51,135 \quad 9,703$

1,337

9,096

13,176

$29,679 \quad 13,917$

$67,500 \quad 11,523 \quad 5,211 \quad 18,491$

178.00 .313 .60

$642.90 \quad 739.00$

4,195 26, 840

$13,716 \quad 25,449$

$10,824 \quad 15,896$

$\begin{array}{llll}765.80 & 430.20 & 124,900 & 6,792\end{array}$

639.54

430.20

$1,149.70 \quad 2,064.70$

$225,60036,585$

15,563

49,176

1160,794

213,897

158,421

326,926

309,877

$\begin{array}{rrrrrrr}278.00 & 545.00 & 1,171.20 & 103,750 & 16,731 & 18,618 & 26,161 \\ 261.70 & 386.00 & 971.90 & 114,200 & 18,618 & 12,157 & 26,936 \\ 608.33 & 796.27 & 1,424.70 & 336,500 & 63,953 & 47,247 & 67,122 \\ 811.00 & 1,081.00 & 1,403.00 & 252,000 & 48,990 & 106,339 & 59,522 \\ 582.40 & 1,904.90 & 1,656.10 & 259,000 & 29,818 & 24,309 & 39,648\end{array}$

165,760

176,092

514,822

467,451

352,775

$\begin{array}{lllllll}791.00 & 2,058.50 & 2,209.00 & 428,750 & 68,233 & 104,823 & 682,294\end{array}$

682,294

042,257 
One notices that extractive industry and construction have been neglected; transportation (including railway personnel) has been classified under semipublic land used (though railroad property has been neglected in these uses). On the other hand, most of the figures had to be corrected upwards, as information on small numbers was not disclosed; for that very reason, arbitrariness probably never exceeds $1 \%$ or the finally obtained figure. Moreover, it is evident that far better decisions would have been taken, had the required figures been available; we tried anyway, on the basis of published figures, to reach as high a degree of homogeneity as possible, before carrying out the analysis proper.

Figures appear in Table 1 , columns $(G)$ through $(\mathrm{K})$.

\subsection{General shape of the empirical curves}

In order to analyze the data in a simple way, the following remarks should be made.

When equation [17] is rewritten stochastically, one has

$$
\sum_{i} D_{i} S_{i} \equiv E_{i}=\frac{\sum_{i} \alpha_{i}\left(D_{i} E^{-1}\right)^{\beta} e^{\Sigma_{i}} \cdot E}{\sum_{\gamma} \alpha_{\gamma}\left(D_{i} E^{-1}\right)^{\beta \gamma} e^{\Sigma \gamma}} \equiv E
$$

which allows one to compute equation [17] statistically in the "separated" form

$$
E_{i}=\alpha_{i}\left(D_{i} E^{-1}\right)^{\beta_{i}}{ }_{e}^{\sum_{i}}
$$

where $E_{i}$ is a stochastic term exhibiting the ordinary "nice" properties for statistical fitting.

Further, neglecting $\Sigma_{i}$ in [19], and remembering that $D_{i}=S_{i} / E_{i}$, one has

$$
\text { where } \quad \begin{aligned}
\log E_{i} & =\beta_{i}\left[\log E_{i}-\log S_{i}-\log E\right]+\alpha_{i} * \\
& =B_{i}\left(\log S_{i}+\log E\right)+A_{i} \\
\text { whence } \quad B_{i} & =\beta_{i}\left(1-\beta_{i}\right)^{-1} \\
B_{i} & =B_{i}\left(B_{i}-1\right)^{-1}
\end{aligned}
$$

The quantities $S_{i} E$ have been computed; graphs 1 to 4 relate them to the corresponding $\mathrm{E}_{\mathrm{i}}$ figures.

The graphs should normally have displayed a concavity towards the abcissa; on first inspection this does not seem to be the case, except perhaps in their "upper parts".

To test out whether a systematical factor is at work here, we computed the Kendall rank-correlations ${ }^{10}$ of the variables $E S_{i}$ with the percentage of vacant land ${ }^{11}$. It appeared to us that a bias in the curve would have been caused by systematic differences in available land for expansion. The results were as follows. 


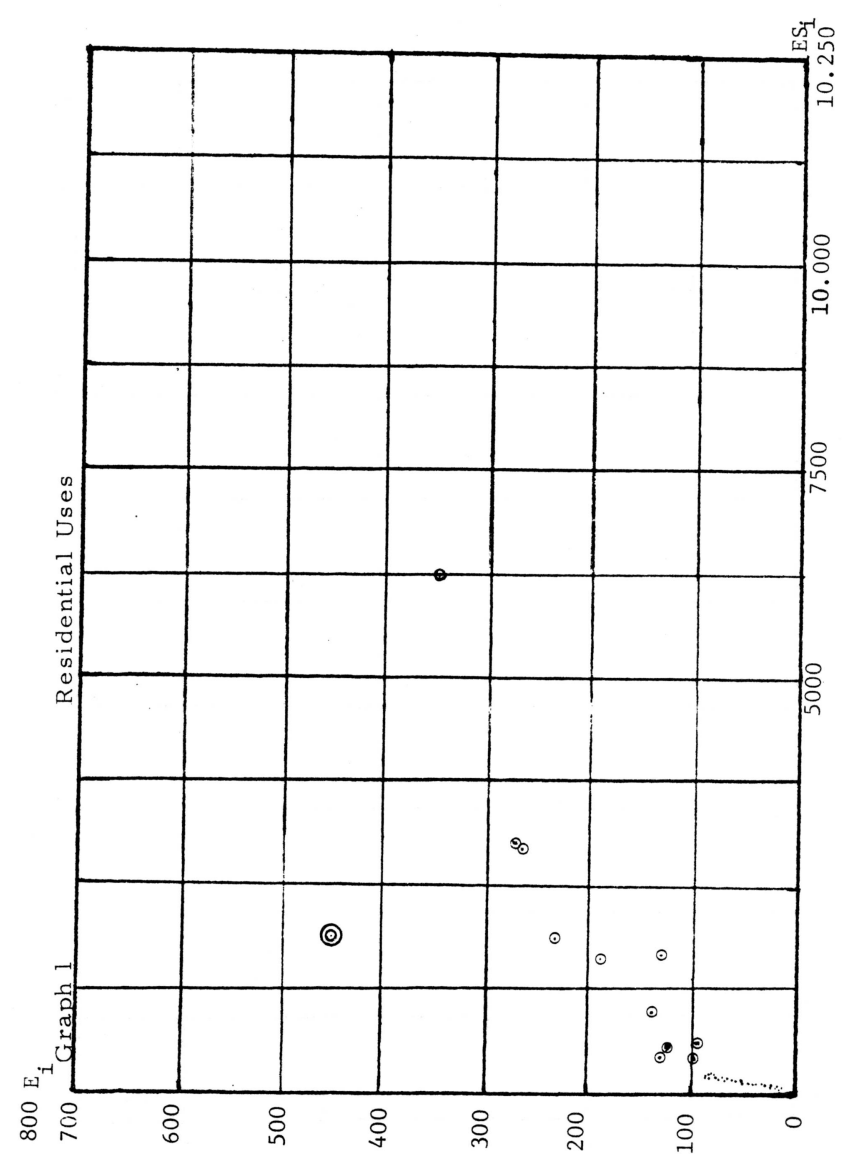




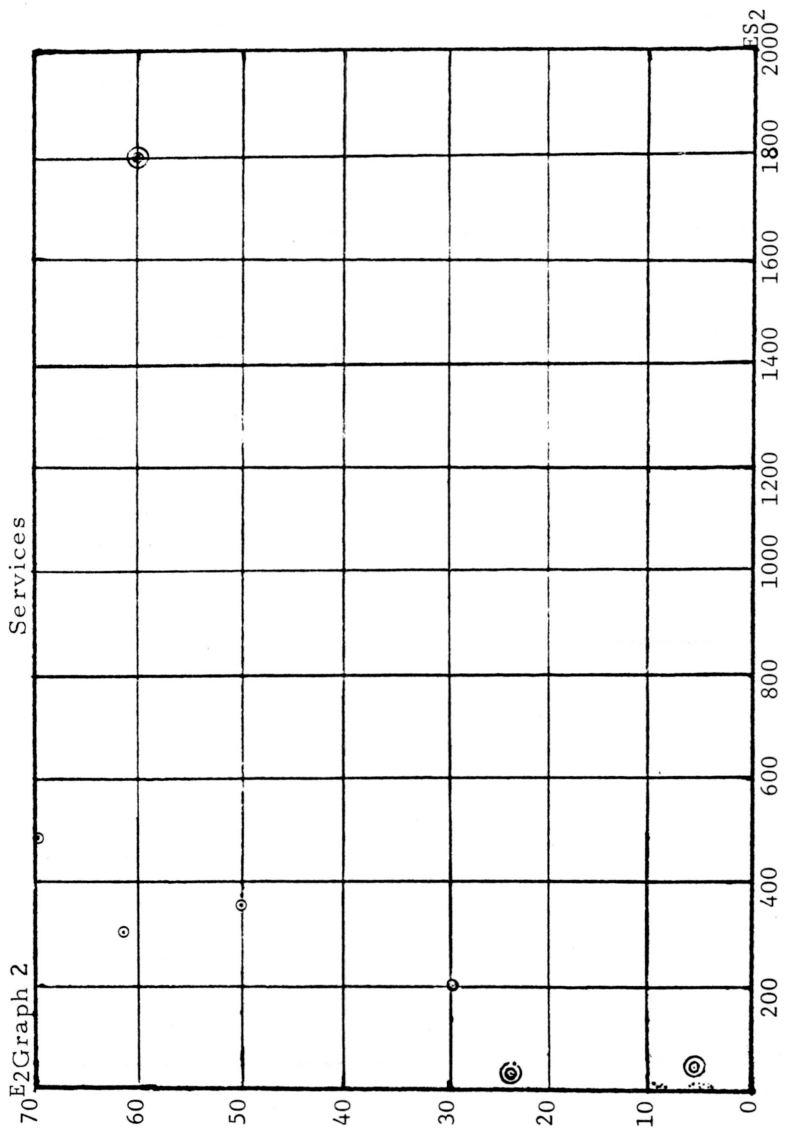




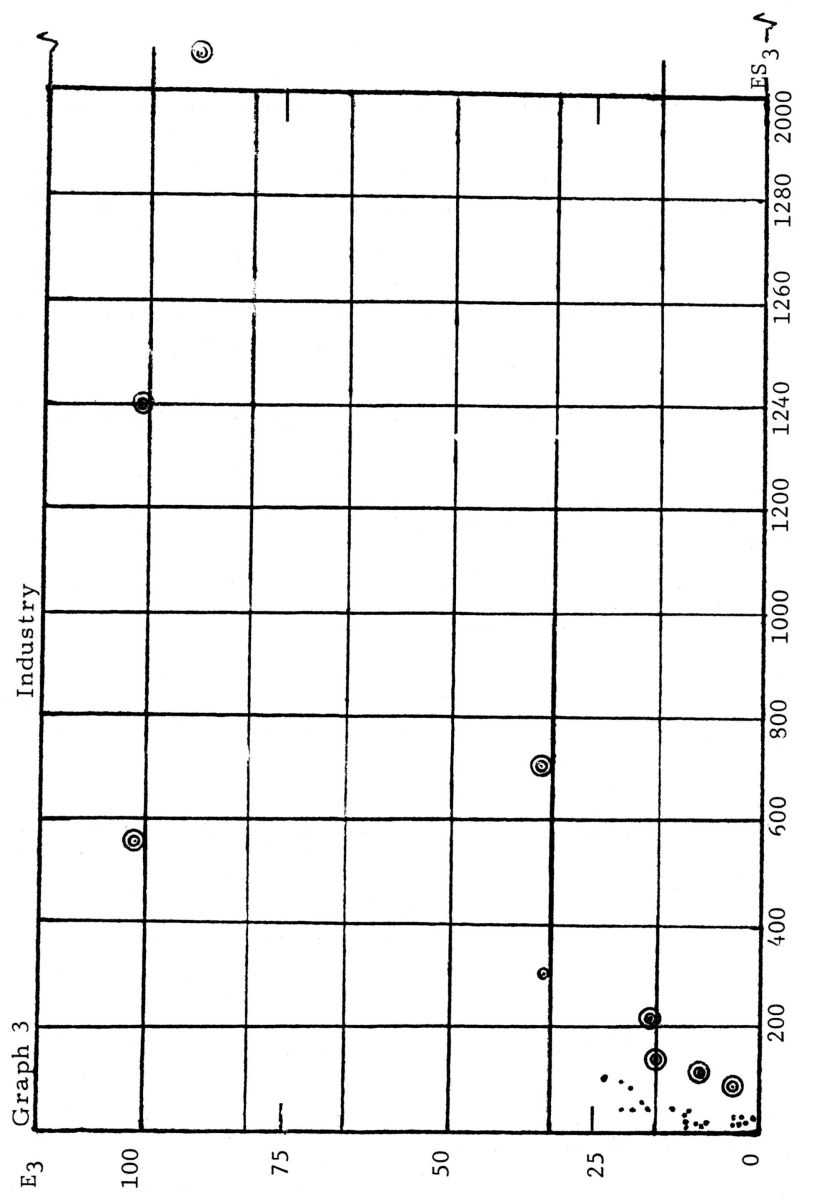




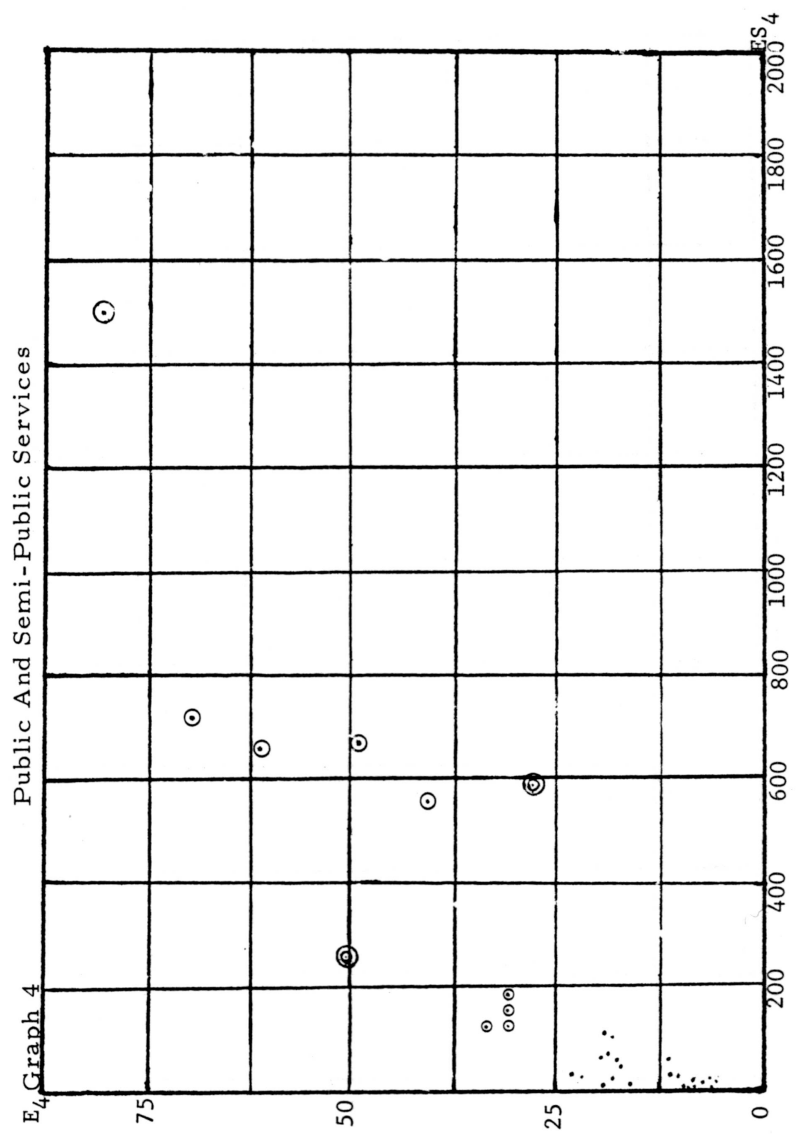




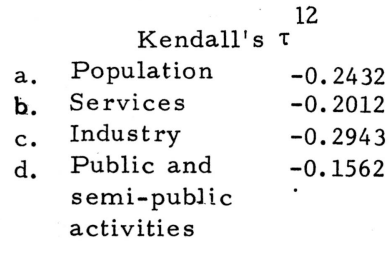

Significance (normal deviates)

$-2.4394$

$-2.0152$

$-2.9545$

$-1.5606$

TABLE 2.

Vacant land ratios (in \%00)

\begin{tabular}{|c|c|c|c|c|}
\hline \multirow{6}{*}{$\begin{array}{l}\text { Baton Rouge, La. } \\
\text { Battle Creek, Mich. } \\
\text { Jefferson City, Mo. } \\
\text { Kankakee, Ill. } \\
\text { Mason City, Iowa }\end{array}$} & & \multirow{6}{*}{$\begin{array}{l}19 . \\
20 . \\
21 . \\
22 . \\
23 .\end{array}$} & \multirow{2}{*}{ Lincoln, Nebraska } & \multirow[b]{2}{*}{2979} \\
\hline & 2607 & & & \\
\hline & 3924 & & Portsmouth, Va. & \\
\hline & 5765 & & Racine, Wis. 3010 & $\begin{array}{l}3010 \\
6614\end{array}$ \\
\hline & 1780 & & St. Petersburg, Fla. & \\
\hline & 6110 & & & \\
\hline Muskogee, Okl. & 3082 & 24. & Schenectady, N. Y. & 2214 \\
\hline Petersburg, Va. & 2595 & 25 . & Topeka, Kansas & 1926 \\
\hline Quincy, Ill. & 1310 & 26. & Corpus Christi, Tex. & 586 \\
\hline Rock Island, Ill. & 4087 & 27. & Des Moines, Iowa & 4799 \\
\hline Roswell, New Mex. & 2927 & & Kansas City, Kansas & 2631 \\
\hline Santa Fe, New Mex. & 8689 & 29. & Oklahoma City, Okla. & 1729 \\
\hline West Palm Beach, Fla. & 4402 & 30. & Richmond, Va. & 3411 \\
\hline Brighamton, N. Y. & 2971 & 31. & Utica, N. Y. & 3381 \\
\hline Davenport, Iowa & 4286 & 32. & Wichita, Kansas & 1853 \\
\hline Decatur, Iowa & 1850 & 33. & Dallas, Texas & 1824 \\
\hline Greenville, S.C. & 4419 & 34. & Dayton, Ohio & 1527 \\
\hline Hamilton, Ohio & 1167 & 35. & Memphis, Tenn. & 3293 \\
\hline Lansing, Mich. & 2480 & $\begin{array}{l}36 . \\
37 .\end{array}$ & $\begin{array}{l}\text { Newark, N. J. } \\
\text { St. Louis, Mo. }\end{array}$ & $\begin{array}{l}1657 \\
1605\end{array}$ \\
\hline
\end{tabular}

The results are significant at the $5 \%$ bilateral level for the first three categories, though $\tau$ does not appear to be exceptionally high.

An other remark flows from inspection of the obviously "outlying" points in Graphs 1 through 4. Trendwise we observed that a lower ordinate is correlated with a lower value of vacant land (call this variable $r$ ). Systematic exploration of the graphs leads to the following conclusions, where + means a positive deviation from the expected curve for $\mathrm{E}_{i}$, and a positive deviation from the overall unweighted mean for the $r^{\prime} s(\bar{r}=3080)$.

\begin{tabular}{rlrl} 
Graph & Observation & Bias & $\frac{\mathrm{r}-\overline{\mathbf{r}}}{-}$ \\
\cline { 2 - 4 } 1. & Newark, 1945 & - & - \\
& Lincoln, 1951 & + & - \\
Kansas City, 1938 & Saint Louis, 1938 & - & - \\
& Corpus Christi, 1951 & - & - \\
Kansas City, 1938 & - & - \\
& Des Moines, 1939 & - & - \\
& Oklahoma City, 1945 & - & - \\
Dayton, 1952 & - & + \\
Memphis, 1939 & + & -
\end{tabular}


$\frac{\text { Graph (cont.) }}{4 .}$

Observation

Oklahoma City, 1935

Des Moines, 1939

St. Louis, 1938

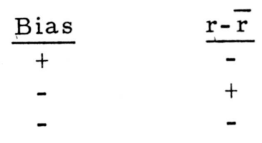

For the 14 cases listed, 7 sign patterns correspond, and 7 diverge. Some of these descrepancies might be due to extrapolation (Kansas City, Des Moines, St Louis), but they don't appear systematically in all four graphs; moreover, some cities have equally low $r^{\prime} s$ without appearing systematically in this discrepancy picture (e.g. the $r^{\prime} s$ for Newark and Saint Louis are nearly the same: 1607 and 1605).

\section{3 Regression analysis}

Two types of regression analysis have been performed in the light of the previous discussion. 14 On the one hand equation [20] has been fitted.by least squares to a set of data not containing the controversial observations. On the other hand an "expanded" equation

$$
\log E_{i}=B_{i}^{*}\left(\log S_{i}+\log E\right)+C_{i}^{*} \log r+A_{i}^{*}
$$

has also been fitted by multiple linear regression on the complete sets of data.

The results are as follows:

\begin{tabular}{|c|c|c|c|c|c|c|c|}
\hline $\begin{array}{r}\text { Land } \\
\text { use } \\
\text { type }\end{array}$ & $B_{i}$ & $\mathrm{t}_{\mathrm{B}}{ }^{*^{15}}$ & $C_{i}^{*}$ & $\mathrm{t}_{\mathrm{C}_{i}^{*}}{ }^{1}$ & $r^{2}, R^{2}$ & $\mathrm{~F}^{17}$ & $\mathrm{~d}^{18}$ \\
\hline a. & 0.5288 & 29.38 & --- & --- & 0.9621 & 863.49 & 1.8086 \\
\hline b. & 0.5099 & 15.59 & --- & --- & 0.8836 & 242.92 & 1.8732 \\
\hline c. & 0.6944 & 10.27 & -- & -- & 0.7901 & 105.41 & 1.8897 \\
\hline d. & 0.4617 & 9.77 & -- & -- & 0.7490 & 95.48 & 1.6427 \\
\hline a. & 0.5342 & 23.94 & -0.0783 & -1.1855 & 0.9527 & 342.17 & 1.5216 \\
\hline b. & 0.4721 & 12.86 & -0.0505 & -0.4388 & 0.8525 & 98.23 & 2.0086 \\
\hline c. & 0.5949 & 9.41 & -0.0793 & -0.3790 & 0.7548 & 55.28 & 1.8498 \\
\hline d. & 0.4201 & 10.7116 & -0.3103 & -2.6716 & 0.8063 & 70.74 & 1.4387 \\
\hline
\end{tabular}

They show the following characteristics:

a) All the $B_{i}^{*}$ coefficients are in the range[0.45-0.70], and highly significant.

b) Introduction of $\mathrm{r}$ does not considerably affect the value of the obtained $B_{i}^{*}$ 's.

c) The $C^{*}$ coefficients are all negative, and, except for case d, nonsignificant. ${ }^{19}$

d) Introduction of $r$, and using complete data, hardly affects the fit obtained, except in case $d$, where the fit is improved.

Taking into account the multiple phases through which the data we re processed, the results obtained are ratheramazing, urban econometrics being generally characterized by low correlation coefficients and non-significant parameters! More refined tests (for non-linearity,e.g.) should be devised; they have not been used at this stage of the investigation.

\section{4 Derived parameters}

On the basis of the regression results of equation [21] the following parameters werederived; the ${ }_{i}$ used are average values. 


\begin{tabular}{|c|c|c|c|c|}
\hline Coefficient & & \multicolumn{2}{|c|}{ Type of Land Use } & \multirow[b]{2}{*}{ d } \\
\hline & a & $\mathrm{b}$ & $c$ & \\
\hline $\mathrm{E}\left(\mathrm{E}_{i}\right)_{i} / \mathrm{E}(\mathrm{E})$ & $\begin{array}{r}-1.1468 \\
1.0449\end{array}$ & $\begin{array}{r}-0.8943 \\
0.7924\end{array}$ & $\begin{array}{r}-1.4685 \\
1.3666\end{array}$ & $\begin{array}{r}-0.7244 \\
0.6255\end{array}$ \\
\hline$\sigma_{i \gamma}$ & & & & \\
\hline $\begin{array}{l}\mathrm{a} \\
\mathrm{b}\end{array}$ & $\begin{array}{r}-0.9892 \\
---\end{array}$ & $\begin{array}{r}1.9392 \\
-17.6180\end{array}$ & $\begin{array}{l}2.5134 \\
2.2609\end{array}$ & $\begin{array}{l}1.7693 \\
1.5168\end{array}$ \\
\hline c & --- & --- & -21.4134 & 2.0910 \\
\hline d & -- & --- & --- & -12.4262 \\
\hline
\end{tabular}

The main results of these calcultations are:

a) Residential and industrial land uses are more space-elastic than land uses by services (private, semi-public or public)

b) All land uses are competitive.

c) Industrial land use and land use for private services have large own substitution elasticities, meaning a high sensitivity to land use pressures.

\section{Uses of the Model}

Let us briefly summarize our findings.

a. Density appears as a significant factor in explaining land use patterns; it should be integrated in theoretical models of the city. 20

b. Land uses are competitive in the central city, at least at the level of aggregation which was used in this study.

c. Vacant land is not a significant explicative factor of land use; for public and semi-public uses, it is significant, but appears to be rather a consequence of the observed land-use pattern, than an explaining factor.

The model itself could be used for the following purposes:

a) to measure how sectors compete for use of urban land;

b) given forecast of $E$ and of the $D_{i}$ 's, to project the sectorial $S_{i}$ 's and $E_{i}^{\prime} s$.

It is evident that its operational use depends on more adequate and more disaggregated data. 


\section{FOOTNOTES}

${ }^{1}$ Not guoting the urban base studies, one can think of $\mathrm{G}$. Alexanderson, The Industrial Structure of American Cities (University of NebraskaPress, 1956), I. Morrisset, PAPRSA, Vol. IV, 1958, pp. 238-258; E. Ullman and M. F. Dacey, The Minimum Requirements Approach to the Urban Economic Base, PAPRSA, Vol. VI, 1960, pp. 175-194.

2 J. Paelinck, Contribution a 1 etude de systemes lineaires de depense, (Namur Faculty of Economics, 1964); and: Sensibilite de projections de la demande a moven terme a des variations des prix relatifs ( $\mathrm{Paris}$, Economie Appliquee, 1966, pp. 353-378.

${ }^{3}$ This property is still valid in a stochastic system.

${ }^{4}$ Negativity is due to the income effect; see equation

$5_{\sigma_{i i}}<$ for $\beta_{j}<0, \forall_{j}$.

${ }^{6}$ All these elasticities are variable, as they are functions of the $a_{i}$.

${ }^{7}$ Bartholomew, H: Urban Land Uses (Cambridge, University Press, 1932); and: Land Uses in American Cities (ibid, 1955); Chapin, F. Stuart Jr.: Urban Land Use Planning (N. Y., Harper, 1957; 2nd ed. Urbana, University of Illinois Press, 1965). We would like to thank our colleague, W. Porter, for having brought this literature to our attention.

8 This choice has been made on the basis is of availability of employment data, only published for cities of 25,000 and over; see hereafter. The cities are listed in table 1 of this study, (A).

${ }^{9}$ Also on the basis of existing and matching employment data.

${ }^{10}$ M. G. Kendall, Rank Correlation Methods, London, Griffin, 1955.

${ }^{11}$ Source: Bartholomew (1955); see table 2 .

12

We recall that $1 \leq \tau \leq 1$.

${ }^{13}$ The description runs from left to right on the graph.

${ }^{14}$ They have been process through the M.I.T. Troll (0) system; Professor Aaron Fleisher kindly provided the necessary computer time.

${ }^{15}$ Student's t

${ }^{15}$ Student's t

${ }^{16}$ Simple or multiple squared correlation coefficient

${ }^{17}$ Fisher-Snedecor F-ratio

${ }^{18}$ Durbin-Watson's d-statistic (autoregression of disturbances)

${ }^{19}$ This is exactly opposite to the results of the t-tests previously reported (section 4.2) 
${ }^{20} \mathrm{Cfr}$. J. Paelinck, Some dynamic urban growth models, paper read at the Copenhagen meeting of the R.S.A., August 1969, (to be published in PAPRSA). 